\title{
METABOLIC EFFECTS OF SODIUM RESTRICTION AND THIAZIDES IN TETRAPLEGIC PATIENTS ${ }^{1}$
}

\author{
By Jacqueline Claus-Walker, Ph.D., David Cardus, M.D., Donald Griffith, M.D., \\ and L. S. HalsTEAD, M.D. \\ Departments of Rehabilitation, Physiology, Biochemistry, Community Medicine and Urology, \\ Baylor College of Medicine; and the Neuroendocrine Laboratory, and Work Tolerance \\ Laboratory, Texas Institute for Rehabilitation and Research, Houston, Texas, U.S.A.
}

Abstract. The metabolic effects of sodium restriction, alone or with thiazide, were studied in 12 healthy subjects, in 24 tetraplegics during the initial 8 months of paralysis (early) and in 16 others during the subsequent period (late). The diuresis caused by both treatments led to more haemoconcentration in early than in late patients. In contrast with the healthy subjects on low sodium, the tetraplegics had a delayed urinary sodium retention and no fall in calciuria. During thiazide, urinary sodium depletion occurred early and the urine calcium fell after 3 days in all tetraplegics. During both treatments, aldosterone and renin increased more in early patients than in the other groups. The clinical implications of inducing dehydration and a sustained stimulation of the reninangiotensin-aldosterone axis in recently injured tetraplegics with severe orthostatic hypotension are discussed.

Key words': Sodium restriction; Thiazides ; Tetraplegic patients.

\section{Introduction}

TETRAPLEGIC patients extensively paralysed by cervical spinal cord injuries undergo a redistribution of body fluids and electrolytes, which may be in part related to their high plasma renin activity and aldosterone (Claus-Walker et al., I969; Johnson et al., I97I; Mathias et al., 1975). Tetraplegics have hypercalciuria at onset (Claus-Walker et al., I975), and are subject to oedema henceforth. During treatment by low sodium and diuretics, many recently injured tetraplegics become reluctant to undergo head-up tilt and wheelchair training. It may well be that the effects of the treatments are modified by the shifts of fluids and electrolytes, and that sodium depletion may aggravate the severe orthostatic hypotension of the early patients by inappropriate stimulation of their over-active renin-angiotensin axis. To test this possibility, the daily biochemical responses to sodium restriction alone, and to sodium restriction combined with thiazide therapy, were studied during the initial 8 months of paralysis (early) and during the subsequent period (late). It was not possible to study the cardiovascular responses to head-up tilt, because during the low sodium intake period, with or without thiazides, most of the patients refused to be tilted, or were tilted to a lesser angle for a shorter time than before.

\section{Method}

Subjects with complete motor transection of the cervical cord were selected on a chronological basis after admission and medical evaluation. In the first experiment to study the effects of sodium restriction, I 2 healthy subjects of similar

1 Supported by grants from the Department of Health, Education and Welfare, RSA \# I6 P 56813/6; and from the Schlumberger Foundation, Houston, Texas. 
age as the patients voluntarily participated in the study. The hospital diet of the patients containing $130 \pm 4 \mathrm{mEq}$ sodium, $85 \pm 3 \mathrm{mEq}$ potassium and $45 \pm 3 \mathrm{mEq}$ calcium was given to the healthy subjects for 3 days; subsequently these subjects, and I I early and 6 late tetraplegics ate a diet containing i 5 to $35 \mathrm{mEq}$ sodium daily for 4 days. In a second experiment, I 3 early and Io late tetraplegics, previously on the high sodium hospital diet, were given the same low sodium diet plus a daily dose of $500 \mathrm{mg}$ chlorothiazide for 5 days. All subjects had a daily fluid intake of 2 litres. Supine blood pressure was measured four times daily in the tetraplegic groups.

Urines were collected on ice daily throughout the experiment. When the patients were out of bed and during intermittent catheterisation, the urine samples were refrigerated as rapidly as collected. After the daily volume measurement, each urine was processed as required for each test and stored frozen. On the last day of high sodium intake and on the 2nd and last day of low sodium with or without thiazide, venous blood was withdrawn from the patients still in bed, between 0700 and $0800 \mathrm{~h}$. The blood samples were immediately processed as required for each test. An haematocrit was obtained prior to and on the last day of each experiment.

Serum and urine sodium and potassium were evaluted by flame photometry (Instrumentation Laboratory, Model I43) and phosphorus by the method of Fiske and Subbarrow (1925). Hydroxyproline was measured by the method of Kivirikko et al. (1967); calcium was measured by atomic absorption; I7-hydroxycorticosteroids and urinary acid labile aldosterone were measured as described previously (ClausWalker, I969); methoxyhydroxymandelic acid by the method of Pisano et al. (I962), and epinephrine and norepinephrine by an isotopic derivative method (ClausWalker et al., 1969). Plasma renin activity was determined using the Angiotensin I $\left({ }^{125} \mathrm{I}\right)$ renin radioimmunoassay kits from New England Nuclear. Plasma aldosterone was evaluated with the assistance of Dr R. Farmer by a radioimmunoassay which uses an aldosterone gammalactone antibody prepared in sheep (Farmer et al., 1973).

The means, the standard errors, and the analysis of variance to assess the significance of the differences were calculated for all comparisons, using Wang $700 \mathrm{~A}$ calculator taped programmes. The differences between groups were assessed by comparing the mean results on the last experimental day. In the low sodium experiment, the healthy were compared to the pooled early and late groups. In both low sodium and low sodium and thiazides experiments, the early and late tetraplegic groups were compared. The changes within groups were assessed by comparing the means obtained on the 3 rd control day of high sodium intake to the means obtained on each experimental day. For the thiazide experiment, days 3 and 4 were pooled.

\section{Results}

In the low sodium experiment, the age range of the healthy group was. 22 to 38 years, in the early tetraplegics, it was I 6 to 40 years, and in the late group, I 6 to 47 years. In the thiazide experiment, the early group age ranged from 16 to 40 years, and the late group from 19 to 47 years.

The duration of the paralysis in the low sodium experiment ranged from 8 to 29 weeks for the early group. The late patients were paralysed 9, I I and I2 months, and 6, 6 and 29 years. In the thiazide experiment, the early subjects were paralysed from 3 to 26 weeks. Among the late ones, three were paralysed for I I months and the others for I, I, 4, 7, 8, Io and 30 years. 


\section{TABLE I}

Mean differences between groups

Significant differences with probability values of $0.05,0.01$ and 0.001 are indicated as $\star$, $\star \star$ and $\star \star \star$

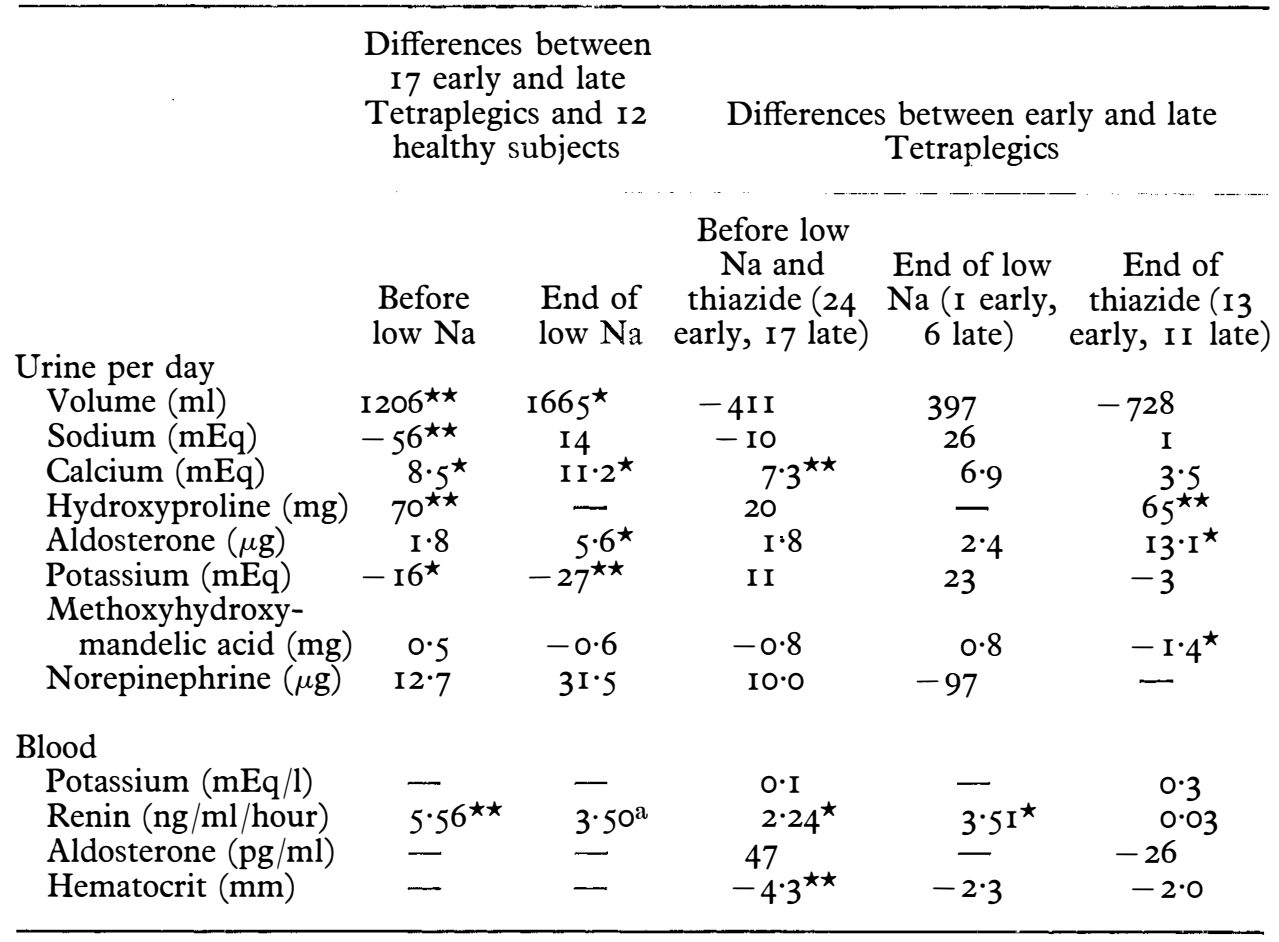

a Data on healthy subjects from New England Nuclear.

\section{Differences between Groups (Table I)}

Prior to the experiments there were many significant differences between the tetraplegic and the healthy groups: urine volume, calcium, hydroxyproline, and plasma renin activity were higher and urine sodium and potassium were lower in the patients than in the healthy group. The few differences between early and late tetraplegics were a higher urine calcium, plasma renin activity and plasma aldosterone and a lower haematocrit in the early group.

On the last day on low sodium, the significant differences between the tetraplegic and the healthy groups were the same as those observed prior to the diet, except for a greater urine aldosterone in tetraplegics and no more difference in urine sodium. At the end of the thiazide treatment, the significant differences between early and late tetraplegics were a higher hydroxyproline and serum potassium and a lower urine methoxyhydroxymandelic acid in the early group. 

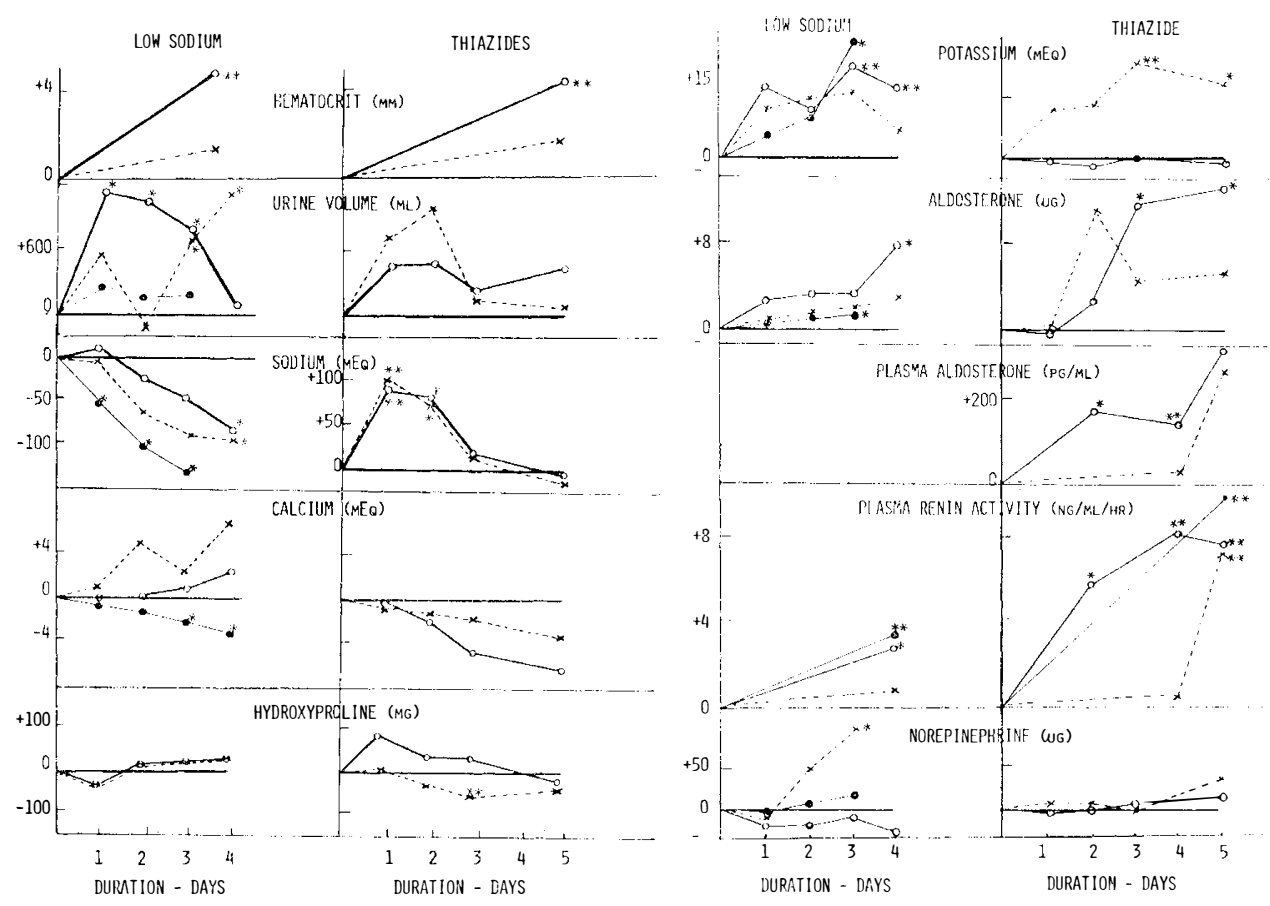

FIG. I

Progressive daily changes above or below control values, during 3 to 5 days of treatment. I2 healthy subjects 0 , I I early tetraplegic patients on low sodium $O$, I3 early tetraplegic patients on thiazides $O$, 6 late tetraplegic patients on low sodium $\times$, IO late tetraplegic patients on thiazides $\times .{ }^{\star}$ for $\mathrm{P}<0.05$ and ${ }^{\star \star}$ for $\mathrm{P}<0.01$.

\section{Differences in the Responses within each Group (Fig. I)}

Low sodium led to minor diuresis increase in healthy subjects, whereas the increases were significant in early tetraplegics on days $I, 2$ and 3 , and in late tetraplegics on day 3. Thiazides led to smaller and insignificant diuresis increases in both early and late patients. Both early groups had increased haematocrits after 4 days of low sodium and after 5 days of thiazide: the increases were minor among late patients. The decreased plasma volume did not induce a lesser mean blood pressure during either treatment.

Low sodium produced an immediate decrease in urine sodium in the healthy subjects. The decrease in both early and late tetraplegics was significant only on the 4 th day. Thiazides elicited a significant natriuresis on days I and 2, and a small reduction of urinary sodium and a decrease in serum sodium on day 4 in both early and late tetraplegic groups $\left(d=-2.5\right.$ and $\left.-4 \cdot 0^{\star} \mathrm{mEq}\right)$.

On the first day, low sodium led to decreased urine calcium in the healthy group only; reversely, there were minor increases among tetraplegics. Three days of thiazide led to minor decreases in calciuria in early and late patients. There were no serum calcium alterations in either group. 
Low sodium led to minor urine hydroxyproline changes. Results were available only in five patients (early and late). Thiazides elicited a small hydroxyproline decrease after 4 days in early and after 3 days in late tetraplegics.

There were no significant changes in urine phosphorus in any group during either treatment.

Low sodium led to an increase in urine potassium starting on the 3 rd day in the healthy and the early groups; the increase was minor in the late tetraplegics. The reverse occurred during thiazide: only the late patients had increased urine potassium starting on day 3. After 5 days of thiazide the fall in serum potassium was far less in the early than in the late group $\left(d=-0 \cdot 3^{\star}\right.$ in the early $v s .-0 \cdot 7^{\star \star \star}$ in the late).

Low sodium led to small, progressive increases in urine aldosterone in the healthy group. The increase was larger in the early tetraplegics than in the healthy and the late groups. Thiazides elicited a progressive urine aldosterone increase significant on the 3 rd day in early tetraplegics, but the increase was not significant in the late group. Plasma aldosterone started to increase after I day on thiazide in the early patients but was delayed and insignificant in the late group.

Low sodium led to greater increases in plasma renin in four early than in three late patients. The increase in the early tetraplegics was in the same range as in healthy subjects. Thiazide led to a rise in renin starting on the Ist day in the early and on the 5 th day in the late tetraplegics.

During the low sodium, urine epinephrine and norepinephrine and methoxyhydroxymandelic acid (MHMA) increased slightly in the healthy group, whereas the early patients had minor epinephrine and norepinephrine decreases and shortlived MHMA increases. In contrast, the late patients, on the 2 nd and 3 rd day, had increased epinephrine $(d=\mathrm{I} 6$ and $65 \mu \mathrm{g})$, and decreased norepinephrine and MHMA. During thiazides there were minor epinephrine and norepinephrine increases and MHMA decreases in both early and late patients.

There were no significant changes in urinary 17 -hydroxycorticosteroids in any group during either treatment.

\section{Discussion}

The results of this investigation show that sodium deprivation alone induced in early tetraplegics an unexpectedly rapid and large diuresis, and, in late tetraplegics, a large diuresis starting only after 3 days. Thiazide led to irregular diuresis increases in both early and late tetraplegics. The haematocrit was much increased only in the early patients, suggesting that the origin of the fluid loss is mainly blood plasma. Regardless of the diuresis increases, the haematocrit was only slightly above control values in the late tetraplegic groups, suggesting that fluids shifted first into the plasma from non-plasmatic extracellular compartments prior to their removal by the kidney. A loss in blood volume may aggravate orthostatic hypotension in the unadapted early patients, and will justify their reluctance to both treatments. Loss of plasma also increases the blood viscosity and further dehydration will eventually lessen tissue turgescence; both effects are undesirable.

The retention of sodium by both early and late tetraplegics during low sodium occurred with a delay because the patients have high sodium stores (Cardus et al., 1969) although the urine sodium was very low on the 4th day. The thiazides induced immediately a sodium diuresis ending only on the 4th day, and on the last day the urine sodium was the same as before the treatment. Therefore, it is not

I $5 / 1-B$ 
well understood why, during sodium restriction, the calciuria was reduced in the healthy subjects and not in the tetraplegics. It may be related to the inefficiency of the diet toward reducing non-plasmatic extracellular fluid volumes. In contrast, after 4 days on thiazides, the calciuria started to diminish in both tetraplegic groups and the hydroxyprolinuria decreased even earlier, suggesting that low sodium and thiazide, by reducing all extracellular fluid volumes, not only increases the reabsorption of calcium by the proximal tubules (Griffith I97I) but also affects the bone turnover, probably by altering the kinetics of fluid exchanges at the bone level.

There is a greater residual sympathetic activity in early than in late tetraplegics (Claus-Walker et al., I972), and prior to treatments there was more norepinephrine in the urine of the early group. Therefore, the simultaneous increase in norepinephrine and decrease in methoxyhydroxymandelic acid found during sodium restriction in late but not in early tetraplegics suggests that these patients have developed a limited ability to catabolise catecholamines and had probably norepinephrine increments similar to the healthy subjects.

The greater residual sympathetic activity of early tetraplegics (Claus-Walker et al., 1972) may explain their normal increase in plasma renin during both treatments. In contrast, in late patients the renin increases were one-half of normal during low sodium, and normal but delayed during thiazide. More renin generated more angiotensin II, leading to a faster and greater increase of plasma and urine aldosterone in early than late patients. The endogenous aldosterone increased urine potassium in the three groups on low sodium, whereas it had no kaliuretic effect in the early patients on thiazides, although their blood potassium was depressed. This indicates that an abnormality in storage co-exists with the abnormality in potassium release exhibited during succinylcholine (Gronert et al., 1975). As the storage does not involve neurotransmitters, an increased permeability of the atrophying muscle cell membranes could account for the shifts of potassium in early tetraplegia.

Head-up tilt per se leads to increased renin release in healthy subjects, in sodium-depleted healthy subjects and in early tetraplegics (Mathias et al., I975; Sancho et al., 1976), and the bursts of angiotensin II participates in the control of blood pressure in the sodium-depleted healthy subjects and in early tetraplegics (Davis et al., I969; Johnson et al., I971). During sodium depletion the already increased activity of the renin-angiotensin axis of early tetraplegics is still more active. The rise in renin caused by postural changes such as tilt or wheelchair may then be too small to be effective in patients with decreasing sodium stores and therefore less vascular sensitivity to angiotensin and norepinephrine (Ames et al., I965) and inadequate homeostatic mechanisms. Similar mechanisms are probably involved in the reduced tolerance to acceleration caused by hydrochlorothiazides in normotensive man (Pfaff and Newberry, 1972).

To answer the question raised in the introduction, the data indicate that the rapidity and the intensity of the responses to low sodium and to thiazides are inappropriate in early tetraplegic patients, and the metabolic changes may eventually lead to haemoconcentration, orthostatic intolerance, electrolyte imbalance (Edmonds and Jasani, I973), and excessive dehydration.

\section{SUMMARY}

The metabolic and therapeutic effects of sodium restriction, alone or with thiazide, may be altered by the shifts of fluids and electrolytes which occur after 
onset of tetraplegia by spinal cord injuries. This eventuality was examined in 24 tetraplegics during the initial 8 months of paralysis (early) and in 16 others during the subsequent period (late). Urine volume, sodium, calcium, hydroxyproline, phosphorus, potassium, aldosterone, and catecholamines, and blood haematocrit and plasma renin activity were evaluated in I I early and 6 late tetraplegics, and in I2 healthy subjects, 3 days before and 4 days during sodium restriction. The same protocol, plus evaluation of serum electrolytes and aldosterone, was carried out in 13 early and Io late tetraplegics during 5 days on low sodium and thiazide. The pre-existing differences between healthy and tetraplegics, or early and late tetraplegics, were still present on the last day of both treatments. The diuresis caused by the treatments led to more haemoconcentration in early than in late patients. Sodium retention was delayed in tetraplegics on low sodium, and, unlike healthy subjects on low sodium, they had no fall in calciuria. Sodium losses occurred early in all tetraplegics on thiazides, and urine calcium was reduced after 3 days. During both treatments, aldosterone and renin increased in all groups but was larger and more rapid in early patients. This led to a rise in urine potassium, except in early patients on thiazide, although all thiazide-treated patients had a fall in serum potassium. The clinical implications of inducing dehydration and a sustained stimulation of the renin-angiotensinaldosterone axis in recently injured tetraplegics with severe orthostatic hypotension are discussed.

\section{RÉSUMÉ}

Les éffets métaboliques d'une diminution sodique, seule ou avec des thiazide, ont été étudiés chez I2 subjets témoins, chez 24 tétraplegiques durant les 8 premiers mois de paralysie (récent) et chez I6 autres, après cette période (chronique). récents.

L'haêmoconcentration provoquée par la diurèse fut plus prononcée chez les paralysés

Contrairement auz sujets témoins, durant la restriction sodique, les tétraplégiques ont montré un délai dans la rétension sodique urinaire et la calciurie n'a pas baissée.

Durant le traitement avec les thiazides, la dépletion sodique urinaire fut rapide et la calciurie fut réduite après 3 jours, dans les 2 groupes de tétraplegiques.

Les 2 traitements ont provoqué une augmentation de la rénine plasmatique et de l'aldosterone, maximale chez les tétraplegiques recents. Cette étude est terminée par une discussion sur les implications cliniques d'induire une deshydration et une stimulation de l'axe renine-angiotensine--aldosterone chez des malades avec une hypotension orthostatique sévère.

\section{ZUSAMMENFASSUNG}

Metabolische Wirkung der Natriumbeschränkung allein oder zusammen mit Thiaziden wurde in 12 gesunden Personen und 24 Tetraplegikern während der ersten Monate nach der Verletzung (frische) und I6 andere später nach der Verletzung (ältere) studiert. Die dadurch verursachte Diurese führte zur stärker Hämokonzentration in der Gruppe von frischen als auch in der Gruppe von älteren Patienten. Im Gegensatz zu den gesunden Personen hatten nach der Natriumbeschränkung Tetraplegiker verspätete Harnnatriumretenz und keine Verminderung der Kalziurie. Thiazide verursachten frühere Harnnatriumretention und Harnkalziumsenkung nach drei Tagen in allen Tetraplegikern. Während der Natriumbeschränkung mit Thiaziden stiegen Aldosteron und Renin höher in der Gruppe von frischen Patienten als in der anderen Gruppe. Es werden klinische Probleme der verursachten Dehydration und dauernder Reizung der Renin-Angiotensin-Aldosteron Achse in frischen Tetraplegikern mit schwerer orthostatischen Blutdrucksenkung diskutiert. 


\section{REFERENCES}

Ames, R. P., Borkowski, A. J., Sicinski, A. M. \& Laragh, J. H. (I965). Prolonged infusions of angiotensin II and norepinephrine and blood pressure, electrolyte balance, and aldosterone and cortisol secretion in normal man and in cirrhosis with ascites. Fournal of Clinical Investigation, 44, I I 7 I-I I86.

CARDUS, D., SPENCER, W. A. \& MCTAGGART, W. G. (I969). A study of the gross composition of the body of patients with extensive muscular paralysis. Final Report, Social and Rehabilitation Project RD-I87I-M.

Claus-WalkeR, J. L. (I969). A procedure for the measurement of urinary I7-hydroxycorticosteroids, aldosterone acid labile conjugate and free plasma cortisol in patients with chronic illness. Clinical Chemistry, 15, I079-1093.

Claus-Walker, J., Campos, R. J. \& Carter, R. E. (I972). Hypertensive episodes in quadriplegic patients: neuroendocrine mechanisms. Archives of Physical Medicine and Rehabilitation, 53, 47-50.

Claus-Walker, J. L., Carter, R. E., Lipscomb, H. S. \& Vallbona, C. (I969). Daily rhythms of electrolytes and aldosterone excretion in men with cervical spinal cord section. Fournal of Clinical Endocrinology and Metabolism, 29, 300-301.

Claus-Walker, J. L., Collins, V. P. \& McTaggart, W. G. (I969). Measurement of sympathetic neurohormones in the plasma of race car drivers. Aerospace Medicine, 40, I4O-I 4 I.

Claus-Walker, J., Spencer, W. A., Carter, R. E., Halstead, L. S., Meier III, R. H. \& CAMPOS, R. J. (1975). Bone metabolism in quadriplegia: dissociation between calciuria and hydroxyprolinuria. Archives of Physical Medicine and Rehabilitation, 56, 327-332.

Claus-Walker, J., Spencer, W. A., Carter, R. E. \& Halstead, L. S. (In press). Electrolytes and the renin-angiotens in aldosterone axis in traumatic quadriplegia. Archives of Physical Medicine E Rehabilitation.

Davis, W. W., Burwell, L. R. \& BartTer, F. C. (1969). Inhibition of the effects of angiotensin II on adrenal steroid production by dietary sodium. Proc. National Academy of Sciences, 63, 718-723.

EDMONDS, C. J. \& JASANI, B. M. (I973). Total body potassium changes with prolonged diuretic therapy. American Heart fournal, 85, 569-57I.

FARMER, R. W., BROWN, D. H., HowARD, P. Y. \& FABRE, Jr, L. F. (1973). A radioimmunoassay for plasma aldosterone without chromatography. Fournal of Clinical Endocrinology and Metabolism, 36, 460-465.

Fiske, C. H. \& SubBarRow, Y. (I925). The colorimetric determination of phosphorus. fournal of Biological Chemistry, 66, 375-400.

GRIFFITH, D. P. (I97I). Immobilization hypercalciuria: treatment and a possible pathophysiologic mechanism. Aerospace Medicine, 42, I322-1 324.

Gronert, Gerald A. \& Theye, Richard A. (I975). Pathophysiology of hyperkalemia induced by succinylcholine. Anesthesiology, 43, 89-99.

Johnson, R. H., PARK, D. M. \& Frankel, H. L. (I97I). Orthostatic hypotension and the renin-angiotensin system in paraplegia. Paraplegia, 9, I46-I 52.

Kivirikko, K. I., Laitenen, O. \& Prockop, D. J. (I967). Modification of a specific assay for hydroxyproline in urine. Analytical Biochemistry, 19, 249-255.

Mathias, C. J., Christensen, N. J., Corbett, J. L., Frankel, H. L., Goodwin, T. J. \& PEART, W. S. (I975). Plasma catecholamines, plasma renin activity and plasma aldosterone in tetraplegic man, horizontal and tilted. Clinical Science and Molecular Medicine, 49, 29I-299.

Pfaff, J. R. \& NewberRy, P. D. (I972). Effect of hydrochlorothiazide on $+\mathrm{G}_{z}$ tolerance in normotensives. Aerospace Medicine, 43, I225-I229.

Pisano, J. J., Crout, J. R. \& Abraham, D. (I962). Determination of 3-methoxy-4hydroxymandelic acid in urine. Clinica Chimica Acta, 7, 285-29I.

SAncho, J., Re, R., Burton, J., BARger, A. C. \& Haber, E. (1976). The role of the reninangiotensin-aldosterone system in carciovascular homeostasis in normal human subjects. Circulation, 53, 400-405. 